\title{
Structure Formation of Hypereutectic Al-Si-Alloys Produced by Laser Surface Treatment
}

\author{
Sergey Nikolaevich Grigoriev ${ }^{1}$ - Tatyana Vasilievna Tarasova ${ }^{1,}{ }^{*}-$ \\ - Galina Olegovna Gvozdeva ${ }^{1}$ - Steffen Nowotny ${ }^{2}$ \\ ${ }^{1}$ Moscow State University of Technology "STANKIN", Russian Federation \\ ${ }^{2}$ Fraunhofer IWS, Germany
}

\begin{abstract}
Using a coaxial laser cladding process AISi $(X=30,40,60)$ clad tracks were produced. The mechanisms of structure formation in Al-Si alloys during laser cladding were studied. Particle size distribution, surface morphology and microstructure of the initial powders were investigated. The influence of the chemical composition of the powder material on the structure and the microhardness of the coating has been shown, as well as the influence of processing parameters on the microstructure and the geometry of the resulting tracks. Conclusions about the technological possibility of manufacturing single tracks with widths of $<500 \mu \mathrm{m}$ based on an Al metallic matrix bearing a Si content ranging from 30 to $60 \mathrm{wt} . \%$ Si have been made.
\end{abstract}

Keywords: laser processing, Al-Si-alloys, laser cladding, powder metallurgy

\section{O INTRODUCTION}

Technologies used in modern industry must be flexible, energy efficient and, in particular, materialsaving. Additive manufacturing processes, such as selective laser melting [1] and [2] or directed material deposition [3] and [4], build up parts by adding materials layer-by-layer, using a CAD model [5]. These technologies use less material than conventional techniques; therefore, they are superior to alternative processes particularly for the generative manufacturing and the repair of the components on a micro-scale.

Laser surface cladding (LSC) is a material deposition process that uses a high-powered laser beam to melt the added material (usually in the form of a powder) and a thin layer of the substrate to form a coating on the surface. LSC via coaxial powder injection has found broad industry applications for wear protection materials [6]. New laser beam sources (disk laser) provide beam parameters that offer considerable potential for high precision cladding (weld track width $<1 \mathrm{~mm}$ ).

Hypereutectic Al-Si alloys have found application in the manufacture of tools [7] and automotive engine components [8]. The wear resistance of these alloys increases with increasing of the $\mathrm{Si}$ content. However, the Si content is limited to $20 \mathrm{wt} . \%$ in conventional casting processes because of the formation of large primary Si particles (about $30 \mu \mathrm{m}$ ), which reduce the mechanical properties of these alloys. The LSC of Al$\mathrm{Si}$ alloys has attracted considerable interest in recent decades, because it leads to structure refining by rapid solidification [9]. However, all the experiments were based on specimens with a single track width about 3 to $5 \mathrm{~mm}$. In the present work, the authors investigate the possibility of single track manufacturing with widths of $<500 \mu \mathrm{m}$, based on an Al metallic matrix bearing a Si content ranging from 30 to $60 \mathrm{wt} . \% \mathrm{Si}$.

\section{EXPERIMENTAL METHODS}

AlSi-alloys powders with silicon content of 30,40 and $60 \%$ (AlSi30, AlSi40 and AlSi60 respectively) obtained by gas-atomization were used as coating materials for the following reasons. Firstly, the primary Si particles may serve as hard reinforcements to metal matrix composites (MMC) and their size can be controlled by process treatment parameters. Secondly, metal powders obtained via gas-atomization offer a perfectly spherical shape combined with a high cleanliness level. As will be shown below, these factors are essential for providing the desired level of technological properties. Substrates were cut from a rolled plate of commercial alloy (AA6060) with a nominal composition (wt.\%): 0.35 to $0.6 \mathrm{Mg}, 0.3$ to $0.6 \mathrm{Si}, 0.1$ to $0.3 \mathrm{Fe}$, and $\mathrm{Al}$ in balance; their size is $50 \times 30 \times 10 \mathrm{~mm}^{3}$. To increase the absorption of the laser beam, the substrates were ground with 60 -grit $\mathrm{SiC}$ paper and cleaned in acetone in an ultrasonic bath prior to cladding.

A continuous $\mathrm{Yb}$ :YAG $1 \mathrm{~kW}$ disc laser was used for the coating deposition. The spot size of the laser beam on the surface of the substrate for cladding was $50 \mu \mathrm{m}$. Powders were injected through a coaxial nozzle. A coaxial jet of argon gas was used to protect the melt pool from contamination and oxidation. The optimal shielding gas feed rate was determined experimentally and set at 5 1/min. Argon (Ar) was used as a carrier gas. The feed rate varied in from 2 to 10 
$1 / \mathrm{min}$. The processing parameters varied from 150 to $250 \mathrm{~W}$ laser power, 800 to $900 \mathrm{~mm} / \mathrm{min}$ beam speed, and 4 to $10 \mathrm{~g} / \mathrm{min}$ powder feed rate. The symbols used for the study of the geometrical characteristics of the cladding track are shown in Fig. 1.

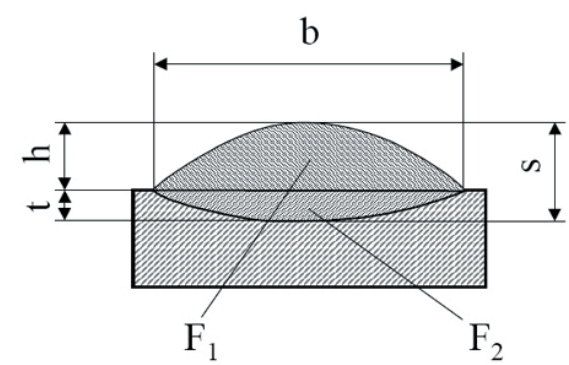

Fig. 1. Cladding track diagram: $b$ - clad track width; $h$ - clad track height; $s$ - clad track thickness; $F_{1}$-clad area; $F_{2}$ - molten area (dilution $\left.\mathrm{y}=\left(\mathrm{F}_{2} /\left(\mathrm{F}_{1}+\mathrm{F}_{2}\right)\right) \cdot 100 \%\right)$

The particle size distribution of the investigated powders was determined with an OCCHIO 500nano microscope with integrated "Callisto" software used for statistical data processing. Phases of the initial powders were identified by X-ray diffraction analysis using an ALR X'TRA diffractometer equipped with "WinXRD 2.0-8c" software and the "ICDD PDF2" database of reference radiographs (2010). The radiation of copper anode $(\mathrm{Cu} \mathrm{K \alpha})$ was used for the conduction of measurements (capture mode: $30 \mathrm{~mA}$, $40 \mathrm{~kW})$.

The transverse sections of the clad tracks (in the plane perpendicular to the laser tracks) were cut for microstructural examinations. Powder samples for metallographic observation were cold-mounted and mechanically polished; a cross section was etched with Keller's reagent. A Leica MEF4M standard optical microscope was employed for studying the microstructure of the powders and clad tracks. A VEGA 3 LM scanning electron microscope (SEM) equipped with energy dispersive X-ray analysis was used to investigate the chemical composition of the powders and clad tracks, as well powder surface morphology.

\section{RESEARCH RESULTS AND DISCUSSION}

\subsection{The Research of Powder Materials AISi30, AISi40 and AISi60}

Fig. 2 presents the cumulative frequency distribution of the AlSi30 powder particle size. It was determined that, for the powders of all studied compositions, particle size distribution was similar and corresponded to the normal (or Gaussian) law distribution around a mean particle sized $_{\mathrm{m}}=45$ to $55 \mu \mathrm{m}$.

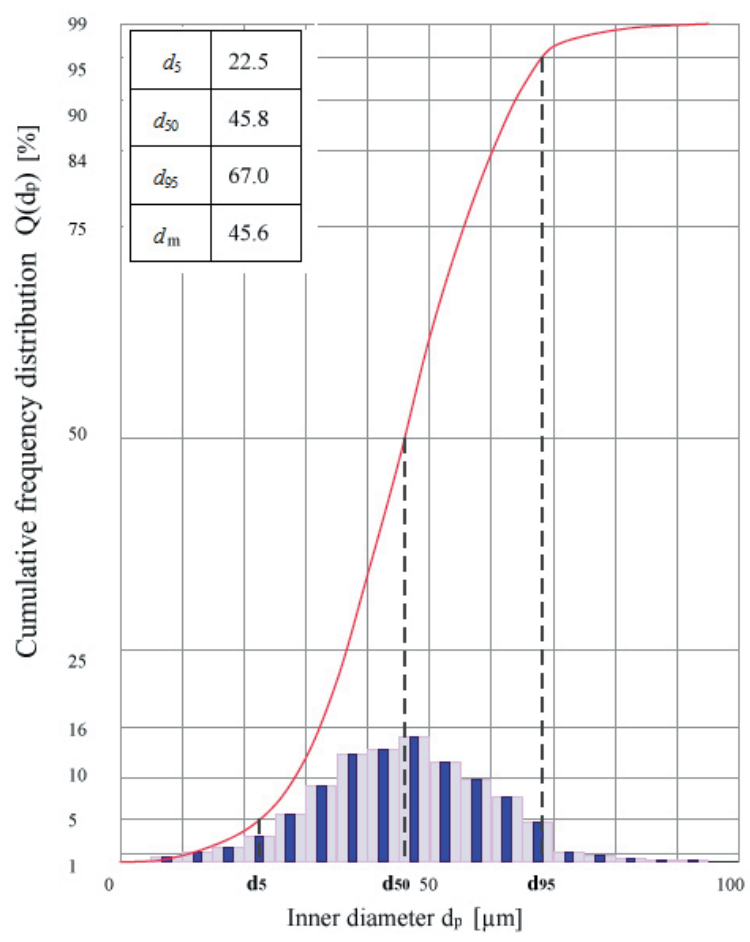

Fig. 2. Cumulative frequency distribution of AlSi30 powder particle size

Table 1. Chemical composition (at. \%) of AlSi $i_{x}$ powders

\begin{tabular}{|c|c|c|}
\hline Chemical element & Al & Si \\
\hline AlSi30 & 66.5 to 67.0 & 33.5 to 33.0 \\
\hline AlSi40 & 55.5 to 56.0 & 44.5 to 44.0 \\
\hline AlSi60 & 32.5 to 33.0 & 67.5 to 67.0 \\
\hline
\end{tabular}

The $\operatorname{AlSi}_{\mathrm{X}}(\mathrm{X}=30,40,60)$ powder particles have a high index of circularity (average values are 69.6; $59.3 ; 71.8 \%$ respectively) and low values of roughness (mean values were $3.3 ; 4.6 ; 1.7 \%$, respectively). The average chemical composition of the investigated powders is presented in Table 1.

Fig. 3 shows a typical surface of gas-atomized powders. The powder particles have a globular shape with a dendritic surface. The dendritic morphology corresponds to eutectic silicon [10]. The primary and eutectic $\mathrm{Si}$ are fine and homogeneously distributed in the Al matrix (Fig. 4). The size and shape of primary $\mathrm{Si}$ particles change as the silicon content in the initial powders increases, from the regular polygon (size about 1 to $5 \mu \mathrm{m}$ ) to a branched structure with high aspect ratio (size $10 \times 30 \mu \mathrm{m}$ ). The comparison of X-ray diffraction patterns of AlSi30, AlSi40 and AlSi60 (Fig. 5, for example, for AlSi30) and reference 
diffraction patterns from the "Pdf-2" database (2010) showed that samples AlSi30, AlSi40 and AlSi60 are two-phase and contain 33, 44 and 67\% wt. Si, respectively, which is consistent with the results of the chemical analysis.

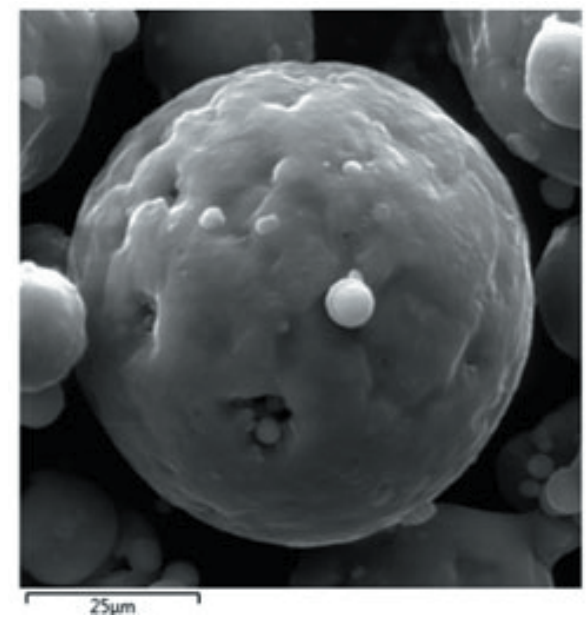

Fig. 3. Morphology of the AISi30 powder particle

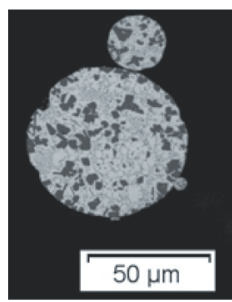

AISi30

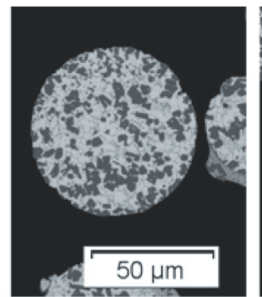

AlSi40

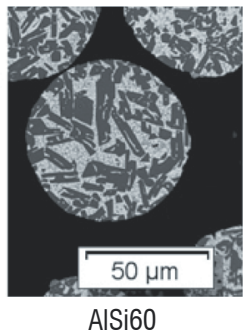

Fig. 4. Microstructure of powders with different silicon content

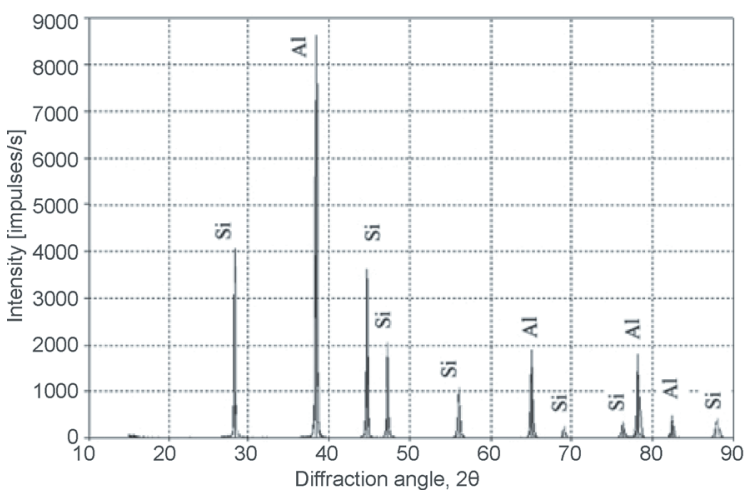

Fig. 5. Diffraction pattern of AlSi30 powder

2.2 The influence of the chemical composition of the powder material on the structure and microhardness of the coating

Fig. 6 presents the microstructure of laser clad tracks as a function of silicon content. A large amount of primary silicon particles is observed over the entire cross sections of the clad tracks. It is noteworthy that the primary Si particles significantly increase in size with increasing silicon content. All clad tracks consist of primary $\mathrm{Si}$ crystals surrounded by $\alpha-\mathrm{Al}$ halos and $\mathrm{Al} / \mathrm{Si}$ eutectic mixing. This non-equilibrium structure was observed in other studies [11]. The Si particles nucleate from the liquid via a heterogeneous mechanism and grow in the undercooled melt. When local concentration of the melt is sufficient, the $\alpha-\mathrm{Al}$ phase nucleates. The growth of the $\alpha$-Al halos results in an increasing $\mathrm{Si}$ content of the remaining liquid phase that leads to the eutectic phase formation. The size of the Si particles is a consequence of their local nucleation and growth conditions. Previous studies [12] and [13] have shown that the molten hypereutectic Al-Si alloys are inhomogeneous at the temperature well above the liquidus. The high cooling rates (typical for the laser cladding) lead to a significant suppression of the diffusion processes. Therefore, large Si particles in the Al-Si alloys with a high Sicontent can increase the inhomogeneity of the molten alloy. It can be expected that this inhomogeneity influences the solidification structure of hypereutectic Al-Si alloys, i.e. the size of the primary Si particle increases with silicon content in alloy from value $<1$ $\mu \mathrm{m}$ when using an AlSi30 alloy to $30 \mu \mathrm{m}$ when using an AlSi60 alloy.

Microstructural examination showed that with the silicon content of $30 \%$ the primary $\mathrm{Si}$ particles are extremely fine, and it is impossible to distinguish primary $\mathrm{Si}$ and eutectic $\mathrm{Si}$ in the coating (Fig. 6a). With a silicon content of $60 \%$ in the alloy structure, the interlayer of aluminum matrix becomes so much thinner that it is accompanied by a degradation of the mechanical properties [14].

A change in the primary silicon particles shape is also observed with increasing Si content in the initial powders: from a regular polygon for the AlSi30 alloy to a branched structure with a high aspect ratio for the AlSi60 alloy (Fig. 6).

In order to examine technological properties of the $\mathrm{AlSi}_{\mathrm{x}}$ powders, single tracks were produced with a high laser power $(\mathrm{P}=400 \mathrm{~W})$, which resulted in an increase in size of the tracks and in dilution with the substrate. Fig. 7 shows the change in the surface morphology of single tracks with increasing silicon content. That many adherent particles can be observed on the coarser track surface in case of the $\mathrm{AlSi}_{\mathrm{x}}(\mathrm{X}$ $=40,60$ ) powders was shown. It was found that the smooth surface of a single track can be fabricated only with the AlSi30 powder. 


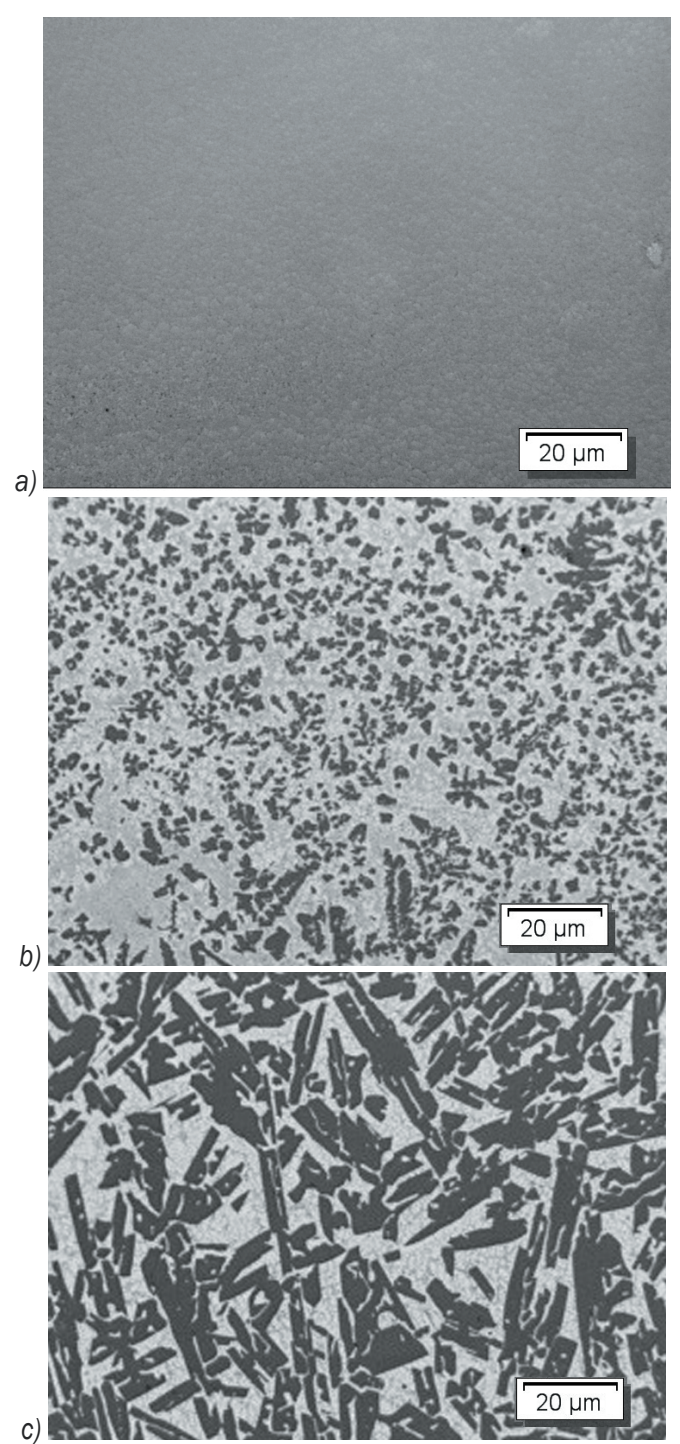

Fig. 6. Microstructure of alloys with increasing silicon content [\%]: a 30; b 40; c 60 ( $P=200 \mathrm{~W}, \mathrm{v}=800 \mathrm{~mm} / \mathrm{min}, P \mathrm{~m}=10 \mathrm{~g} / \mathrm{min})$

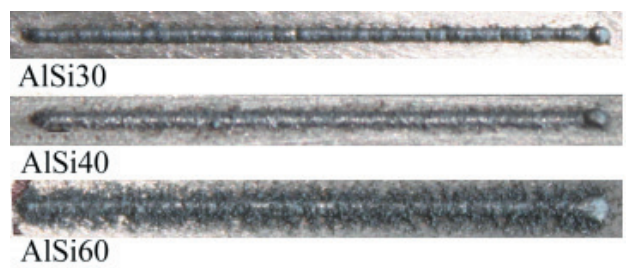

Fig. 7. Change in the surface morphology of single track with silicon content in initial powders $(P=400 \mathrm{~W}, v=800 \mathrm{~mm} / \mathrm{min}$,

$$
\left.P_{m}=1 \mathrm{~g} / \mathrm{min}\right)
$$

A hardness profile of the $\mathrm{AlSi}_{\mathrm{x}}$ tracks is presented in Fig. 8. It is interesting to note that the Si content in the initial powders does not influence the maximal hardness level. A gradual hardness distribution from the surface to their substrate is observed for AlSi30 alloy: from $\mathrm{HV}_{0.05} 190$ down to $\mathrm{HV}_{0.05}$ 80. The hardness of the AlSi40 and AlSi60 coating alloys is constant in the coating region and equal to about HV0.05 180. Some fluctuations on the AlSi40 and AlSi60 hardness profiles are caused by the presence of the larger Si particles than that of AlSi30 alloy, where the hardness curve is gradual. Hardness distribution in the lateral direction of the laser clad tracks is nearly constant. The insignificant difference in the hardness level on the $\mathrm{AlSi}_{\mathrm{x}}$ coatings is explained by presence of the supersaturated solid solution of silicon in aluminum in the case of AlSi30, which takes place at high cooling rates [15] and is consistent with the other studies results [11], [16] and [17].

Due to its superior technological property and sufficient hardness, AlSi30 powder was selected for the further investigations.

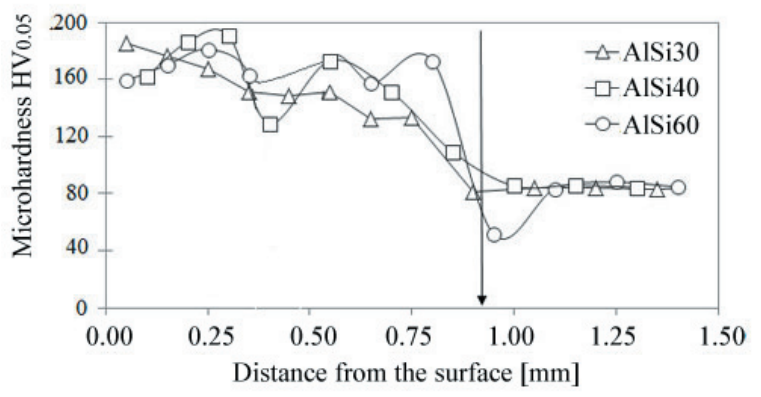

Fig. 8. Microhardness distribution of laser cladding produced from alloys with different Si-content ( $P=400 \mathrm{~W}, \mathrm{v}=800 \mathrm{~mm} / \mathrm{min}, P_{m}=1$ $\mathrm{g} / \mathrm{min})$

\subsection{The Influence of Processing Parameters on the Structure of the Cladding Tracks}

The main parameters of laser cladding that have a significant impact on the structure and properties of the resulting tracks are laser power, beam-scanning speed, and powder feed rate.

The influence of laser power and powder feed rate on the cladding structure is expressed in dilution change. Dilution with the substrate decreases with increases in the powder feed rate and decreases in the laser power. This leads to the larger amount of $\mathrm{Si}$ in the alloy structure. Finally, this results in the formation of the larger primary Si particles. The beam speed influences the distribution of Si particles. The difference in Si particle size between the top and the bottom of the clad tracks increases with increases of beam speed. The combination of laser power decreasing and beam speed increasing results in larger primary silicon particles in the clad bottom, which can lead to the formation of a sharp interface between the 
coating and the substrate, which is often a potential source of weakness (Fig. 8).

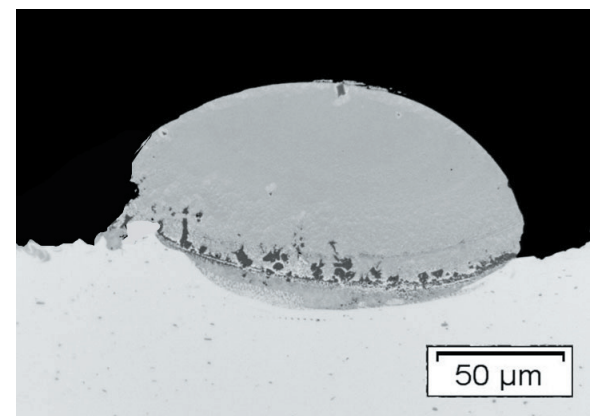

Fig. 8. Optical micrographs of AlSi30 clad track at $150 \mathrm{~W}$ laser power, $900 \mathrm{~mm} / \mathrm{min}$ beam speed and $10 \mathrm{~g} / \mathrm{min}$ powder feed rate

\subsection{The Influence of Processing Parameters on the Geometric Characteristics of the Cladding Tracks}

The influence of the process parameters on the geometric characteristics of the cladding tracks was investigated (the data are given in Tables 2 to 4 ). It was found that laser power is the main parameter of the laser cladding process that influences the formation of single tracks. The width of the clad track and dilution with the substrate are continuously increasing with the increase of the laser power (Table 2). The change of tracks height caused by the change of the laser power is insignificant.

Table 2. Clad track geometry variation vs. laser power ( $v=800$ $\mathrm{mm} / \mathrm{min}, P \mathrm{~m}=10 \mathrm{~g} / \mathrm{min}$ )

\begin{tabular}{cccc}
\hline$P[\mathrm{~W}]$ & $b[\mu \mathrm{m}]$ & $h[\mu \mathrm{m}]$ & $\gamma[\%]$ \\
\hline 150 & 132 & 77 & 37.6 \\
\hline 200 & 156 & 59 & 42.9 \\
\hline 250 & 213 & 61.5 & 59 \\
\hline
\end{tabular}

Beam speed variation in the range of 800 to 900 $\mathrm{mm} / \mathrm{min}$ does not exert an obvious influence on the clad track geometry (Table 3 ). However, dilution with the substrate decreases with increasing of the beam speed.

Table 3. Clad track geometry variation vs. beam speed $(P=150 \mathrm{~W}$, $P_{m}=10 \mathrm{~g} / \mathrm{min}$ )

\begin{tabular}{cccc}
\hline$v[\mathrm{~mm} / \mathrm{min}]$ & $b[\mu \mathrm{m}]$ & $h[\mu \mathrm{m}]$ & $\gamma[\%]$ \\
\hline 800 & 132 & 77 & 37.6 \\
\hline 850 & 120 & 81 & 27.1 \\
\hline 900 & 118 & 64 & 22.7 \\
\hline
\end{tabular}

The clad tracks' height increases and dilution with the substrate continuously decreases with increases of the powder feed rate in the range of 4 to $10 \mathrm{~g} / \mathrm{min}$ at laser power $P=200 \mathrm{~W}$ and scanning speed $v=800$ $\mathrm{mm} / \mathrm{min}$, while the width of the track varies slightly. This is due to the increase of particle flow density and the decrease of direct substrate exposure to the laser beam.

Table 4. Clad track geometry variation vs. powder feed rate $(P=$ $200 \mathrm{~W}, \mathrm{v}=800 \mathrm{~mm} / \mathrm{min}$ )

\begin{tabular}{cccc}
\hline$P_{m}[\mathrm{~g} / \mathrm{min}]$ & $b[\mu \mathrm{m}]$ & $h[\mu \mathrm{m}]$ & $\gamma[\%]$ \\
\hline 4 & 128 & 9.4 & 89 \\
\hline 7 & 130 & 20.8 & 64.5 \\
\hline 10 & 156 & 59 & 42.9 \\
\hline
\end{tabular}

\section{CONCLUSIONS}

1. Powders AlSi30, AlSi40 and AlSi60 meet the requirements for materials for coaxial laser cladding because they have a good flowability (mean sphericity is equal to $66.9 \%$; mean roughness ranges from 1.7 to $4.6 \%$ ) and provide the ability to obtain a single track on a microscale (particle size varies from $22.5 \mathrm{~mm}$ to 67 $\mathrm{mm}$; the mean diameter is $45.6 \mathrm{~mm}$ ).

2. Using a coaxial laser cladding process, $\mathrm{AlSi}_{\mathrm{x}}$ clad tracks with lateral resolution of $<500 \mu \mathrm{m}$ were produced. The coatings consist of silicon primary particles surrounded by $\alpha-\mathrm{Al}$ halos and $\mathrm{Al} / \mathrm{Si}$ eutectic mixing.

3. Si content in the initial powders does not influence on the maximal hardness level in the coating, which is equal to $190 \mathrm{HV}_{0.05}$ for the powders of all investigated chemical compositions.

4. The larger primary Si-particles were formed in the coating structure with increases of the powder feed rate and decreasing the laser power. The difference in Si-particle size between the top and the bottom of the $\mathrm{AlSi}_{\mathrm{x}}(\mathrm{X}=40,60 \%)$ clad tracks increases with increasing beam speed. The primary Si particles in the case AlSi30 are extremely fine, and it is impossible to distinguish primary $\mathrm{Si}$ and eutectic $\mathrm{Si}$ in the coating.

5. The width of the clad track and dilution with the substrate continuously increase with the increase of the laser power. The change of tracks height caused by the change of the laser power is insignificant.

6. The clad tracks height increases and dilution with the substrate continuously decreases with increasing of the powder feed rate in the range of 4 to $10 \mathrm{~g} / \mathrm{min}$ at a radiation power $P=200 \mathrm{~W}$ and a scanning speed of $v=800 \mathrm{~mm} / \mathrm{min}$, while the width of the track varies slightly. 


\section{ACKNOWLEDGEMENT}

This work was supported by the Ministry of Education and Science of the Russian Federation within the state task in the sphere of scientific activity. Experiments on the laser cladding were conducted at the Fraunhofer Institute for Material and Beam Technology.

\section{REFERENCES}

[1] Kovalev, A., Vainshtein, D., Mishina, V., Titov, V., Moiseev, V., Tolochko, N. (2000). Selective laser sintering of steel powders to obtain products based on SAPR-models. Metallurgist, vol. 44, no. 3-4, p. 206209, DOI:10.1007/BF02466080.

[2] Kovalev, A., Mishina, V., Wainstein, D., Titov, V., Moiseev, V., Tolochko, N. (2002). Selective laser sintering of single-phase powder Cr-V tool steel. Journal of Materials Engineering and Performance, vol. 11, no. 5, p. 492-495, DOI:10.1361/105994902770343719.

[3] Gladush, G.G., Smurov, I. (2011). Physics of Laser Materials Processing: Theory and Experiment. Springer-Verlag, Berlin, DOI:10.1007/978-3-64219831-1.

[4] Smurov, I., Doubenskaia, M., Grigoriev, S., Nazarov, A. (2012). Optical monitoring in laser cladding of Ti6A14V. Journal of Thermal Spray Technology, vol. 21 , no. 6, p. 1357-1362, DOI:10.1007/s11666-0129808-4.

[5] Yadroitsev, I.; Bertrand, Ph; Antonenkova, G.; et al.. (2013). Use of track/layer morphology to develop functional parts by selective laser melting . Journal of Laser Applications, vol. 25, no. 5, Article Number: UNSP 052003.

[6] Fominskii, V., Grigoriev, S., Romanov, R. (2012). Effect of the pulsed laser deposition conditions on the tribological properties of thin-film nanostructured coatings based on molybdenum diselenide and carbon. Technical Physics, vol. 57, no. 4, p. 516-523, DOI:10.1134/S1063784212040081.
[7] Bryce, D. (2002). Why offer Aluminum molds for production, from http://www.moldmakingtechnology. com, accessed on 2002-01-04.

[8] Grigoriev, S.N., Krasnovskii, A.N. (2011). Study of the triboengineering characteristics of ultradispersed composite powder materials. Journal of Friction and Wear, vol. 32, no. 3, p. 164-166, DOI:10.3103/ S1068366611030056.

[9] Rohatgi, P. (1991). Cast aluminum-matrix composites for automotive applications. Journal of the Minerals, Metals and Materials Society, vol. 43, no. 4, p. 10-15, DOI:10.1007/BF03220538.

[10] Hong, S-J. (2010). Etching effect on microstructural behavior of gas atomized Al-20 mass.\%Si alloy powder. Materials Transactions, vol. 51, no. 5, p. 10551058, DOI:10.2320/matertrans.M2010008.

[11] Pei, Y.T., De Hosson, J.Th.M. (2000). Functionally graded materials produced by laser cladding. Acta Materialia, vol. 48, no. 10, p. 2617-2624, DOI:10.1016/ S1359-6454(00)00065-3.

[12] Dahlborg, U., Besser, M., Calvo-Dahlborg, M. (2007). Structure of molten Al-Si alloys. Journal of Non-Crystalline Solids, no. 353, p. 3005-3010, DOI:10.1016/j.jnoncrysol.2007.05.031.

[13] Morris J., Dahlborg, U., Calvo-Dahlborg, M. (2007). Recent developments and outstanding challenges in theory and modeling of liquid metals. Journal of NonCrystalline Solids, no. 353, no. 32-40, p. 3444-3453, DOI:10.1016/j.jnoncrysol.2007.05.159.

[14] Kremnev, L. (1996). Critical coefficient of stress intensity and fracture toughness of high-strength tool materials. Metal Science and Heat Treatment, vol. 38, no. 1-2, p. 33-37, DOI:10.1007/BF01153870.

[15] Doubenskaia, M.; Pavlov, M.; Grigoriev, S.; et al. (2013). Definition of brightness temperature and restoration of true temperature in laser cladding using infrared camera. Surface \& Coatings Technology, vol. 220, p. 244-247, DOI:10.1016/j.surfcoat.2012.10.044.

[16] Heigl, R. (2005). Herstellung von Randschichten auf Aluminiumgusslegierungen mittels Laserstrahlung. Herbert Utz Verlag, München. (in German)

[17] Volz, R. (1998). Optimiertes Beschichten von Gußeisen-, Aluminium- und Kupfergrundwerkstoffen mit Lasern. B.G. Teubner Verlag, Leipzig. (in German). 